\title{
O(A) HERÓI(ÍNA) QUE PRECISAMOS SER PARA ENFRENTAR A PANDEMIA DE COVID-19
}

\author{
Marcos Hirata Soares ${ }^{1}$ Júlia Trevisan Martins²
}

\section{RESUMO}

Introdução: A COVID-19, doença capaz de levar a óbito rapidamente, vem causando aos profissionais de saúde, particularmente os de enfermagem, grande impacto moral e psíquico. Dentro desse contexto, a enfermagem se apresenta, mais do que nunca, como linha de frente do cuidado, pelo fato de estar com os pacientes nas 24 horas ininterruptamente, além da falta de Equipamentos de Proteção Individual em vários locais. Desenvolvimento: Diante desta realidade, a presente reflexão teórica tem como objetivo refletir sobre a pandemia de COVID-19 e suas implicações para o processo de trabalho de enfermagem, sob o enfoque da Psicologia Analítica, a partir do referencial teórico proposto por Carl Gustav Jung. Considerações finais: A reflexão contribuiu para que os heróis da enfermagem, muitas vezes desconhecidos e pouco valorizados, possam refletir, a partir do referencial teórico apresentado, sobre seu papel profissional, buscando, neste momento, sua ascensão e reconhecimento perante a sociedade, diante da catástrofe mundial atual, coincidentemente no ano em que a profissão busca, mundialmente, seu empoderamento por meio da campanha mundial Nursing Now.

Descritores: Saúde do Trabalhador; Infecções por Coronavírus; Pandemias; Saúde Mental.

\footnotetext{
${ }^{1}$ Enfermeiro. Doutor em Enfermagem Psiquiátrica. Professor Adjunto de Enfermagem Psiquiátrica e Saúde Mental da Universidade Estadual de Londrina (UEL), Paraná, Brasil. Endereço eletrônico: mhirata@uel.br ORCID: 0000-0002-1391-9978

${ }^{2}$ Enfermeira. Doutora em Enfermagem. Professor Associado de Fundamentos de Enfermagem da Universidade Estadual de Londrina (UEL), Paraná, Brasil. Endereço eletrônico: jtmartins@uel.br ORCID: 0000-0002-6383-7981
}

\section{Autor Correspondente}

Marcos Hirata Soares

Endereço: Av. Robert Koch, 60, CCS-Departamento de Enfermagem, Data de submissão: 13/05/2020

Vila Operária, Loondrina-PR, Brasil.

Data de aceite: $02 / 06 / 2020$

E-mail: mhirata@uel.br

\section{Como citar esse artigo}

Soares MH, Martins, JT. O(A) herói(ína) que precisamos ser para enfrentar a pandemia de COVID-19. Advances in Nursing and Health [Internet]. 2020; 2(2): 1-13. 


\section{INTRODUÇÃO}

Ao invés de grandes expectativas e sonhos, o progresso da sociedade contemporânea tem revelado o quão fatal é o nosso dia a dia. Tem se tornado ameaça de mudança inevitável que nos guia à crise e tensão contínuas, ao invés da paz e repouso. Sendo incapazes de reduzir o ritmo espantoso de tal mudança, muito menos de prever e controlar sua direção, nós nos concentramos no que podemos fazer ou influenciar. Tentamos minimizar o risco de nós, pessoalmente, ou dos que nos são próximos e queridos, de serem afetados pelos incontroláveis e inúmeros perigos que o mundo na pandemia e sua economia globalizada nos reservam ${ }^{(1)}$.

É verdadeiro que a insegurança vivenciada por nós atualmente nunca foi tão imensa e carregada de muitos medos como: o medo de não conseguir manter seu emprego; o medo de adoecer; o medo de contaminar seus familiares, ou, pior ainda, de ver os entes queridos falecerem, sem nada poder fazer. No entanto, quando a insegurança se vai, a espontaneidade, a flexibilidade, as boas relações interpessoais, a capacidade de resolver conflitos, a resiliência, etc. tendem a desaparecer também. São nos momentos de crises que tais atributos como esses, considerados como indicadores de saúde mental positiva no trabalho(2), surgem ainda mais fortalecidos. A alternativa à insegurança não é a tranquilidade total, mas o tédio da ausência de desafios e da falta de criatividade de todos nós. O quanto cada um de nós tem estado preso às rotinas, perdendo a essência daquilo que realmente é importante? O quanto nos sentimos tão frágeis e impotentes nestes últimos tempos? Mas, são também nos piores momentos de crise que o ser humano é capaz de demonstrar seus maiores potenciais.

É possível compreender o momento atual sobre diversas óticas filosóficas e teóricas. Diversos modelos estatísticos podem explicar e até prever os prováveis cenários futuros de nossas ações. Porém, qual dos diversos modelos teóricos nos torna capaz de superar nosso medo, mesmo quando ele parece ser tão real e certo, e nos impulsiona a ter atitudes criativas e de resposta ao problema atual?

Para responder a essa indagação, traçou-se o objetivo de refletir sobre a pandemia de COVID-19 e suas implicações para o processo de trabalho de enfermagem. 
Trata-se de um estudo de reflexão teórica, exploratório e descritivo, sob o enfoque da psicologia analítica, a partir do referencial teórico proposto por Carl Gustav Jung(3-5).

Denota-se que a teoria da psicologia analítica é complexa. Assim, de forma extremamente sintética, os conceitos expostos aqui serão apenas os denominados de mito, arquétipo e símbolo. Em outras palavras, está sendo proposto um recorte teórico e uma reflexão sobre a situação atual vivenciada no Brasil e no mundo todo, particularmente pela enfermagem.

\section{DESENVOLVIMENTO}

\section{O mito, arquétipo e o símbolo nas}

\section{sociedades humanas}

Em todas as culturas do mundo afora, os mitos humanos têm inspirado as pessoas, fazendo com que criem e inovem nas mais diversas áreas das ciências, filosofias e artes. Os mitos, narrados para as crianças, principalmente na forma de estórias e contos de fada, contêm elementos denominados de símbolos - produções espontâneas da psique humana carregados de significados subjetivos transmitindo mensagens do inconsciente à consciência.
Segundo Jung, o inconsciente é a fonte_de criatividade humana. Dessa forma, acessar o inconsciente favorece o desenvolvimento humano e promove sua evolução(3-5).

Jung, então, em suas obras, expõe que qualquer mitologia humana é resultado da projeção de aspectos inconscientes, ou seja, as narrativas míticas tanto nos fascinam como nos assustam, justamente porque estão impressos ali aspectos de nossa psiquê. Por exemplo, a mitologia grega/romana, na qual os diversos deuses e deusas são descritos como pessoas com atributos comportamentais e sentimentais humanos(4).

Influenciado pela cultura grega/romana, Jung incorporou o termo "arquétipo" para explicar as tendêneias psicológicas do ser humano, já que, ao seu entender, essas se repetem de forma padronizada, delineando a personalidade de cada sujeito. Cada um de nós tem sua personalidade moldada por determinadas formas de sentir, agir, pensar e ser, existindo, então, infinitos arquétipos para praticamente todas as situações vividas pela humanidade servindo como aprendizado ou lições oriundas das gerações passadas para as gerações presentes e futuras(4). 
No contexto vivido atualmente, um arquétipo constituinte de nossa psique é denominado de Arquétipo do Herói, descrito como Jornada do Herói, o qual pode ser identificado na grande maioria das sagas de heróis em lendas, mitos, contos de fada e filmes. São 12 etapas sequenciais, ou seja, o herói só consegue prosseguir em sua jornada após superar as anteriores. A palavra "herói" vem do grego, que significa "proteger e servir". Um Herói é alguém que está disposto a sacrificar suas próprias necessidades em benefício dos outros ${ }^{(6-7)}$.

Em termos psicológicos, o arquétipo do Herói representa a capacidade de transcender a si, buscando sua identidade e totalidade. Os heróis não são seres perfeitos e, como qualquer outra pessoa, iguala-se a qualquer um de nós. Somos todos Heróis, enfrentando guardiões e monstros internos, contando com o apoio de aliados. Quando exploramos nossa própria psique, encontramos professores, guias, demônios, deuses, companheiros, servidores, bodes expiatórios, mestres, sedutores, traidores e auxiliares como aspectos de nossas personalidades ou como personagens de nossos sonhos. Todos os vilões, amigos e inimigos do Herói podem ser encontrados dentro de nós mesmos. A tarefa psicológica que todos enfrentamos é integrar essas partes separadas em uma entidade completa e equilibrada. O Herói que se encontra separado de todas essas partes de si mesmo deve incorporá-las para se tornar um ser integral(7).

O verdadeiro heroísmo surge nas histórias das quais o herói se dispõe a correr o risco de que sua jornada possa levar à perda ou à morte. Como um soldado que sabe que, ao se alistar, aceita em dar a vida por seu país, caso seja necessário, o Herói aceita a possibilidade de sacrifício. Os Heróis que funcionam melhor são os que experimentam o sacrifício. Ao longo do caminho, pode ser que tenham que entregar a amada, filhos ou um amigo, ou podem ter que desistir de algum vício, um luxo ou um costume como preço para entrar em uma nova vida. Pode ser que tenham que devolver parte do que ganharam no Mundo Especial. Podem voltar ao ponto de partida trazendo tesouros, elixires, comida ou conhecimento que dividem com o resto do grupo(6). $^{(6)}$

o modelo

arquétipo

\section{propriamente dito}

Apresentaremos a descrição do funcionamento de seu modelo arquetípico, enquadrando-o, com algumas limitações, 


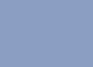

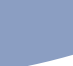

dentro do contexto atual da pandemia de COVID-19, e no contexto do trabalhador de enfermagem e/ou profissional de saúde que está lidando com esta doença.

\section{O chamado da aventura}

Nesta fase é onde se inicia o desafio. O herói, por acaso, entra em contato com forças além de sua compreensão. Alguém mais sábio e experiente explica o fato e faz o convite para que ele enfrente o desafio proposto. Nesse caso, podemos fazer um paralelo com um hospital que inaugurou uma unidade para internação de vítimas da COVID-19 e busca por profissionais que desejam trabalhar na instituição.

Nessa busca, os profissionais da equipe de enfermagem são essenciais, sob a coordenação e liderança executada pelo enfermeiro. Após o recrutamento, dá-se início ao processo laboral desses profissionais que, neste momento, se configuram em realizar o treinamento de como prestar cuidados aos pacientes com COVID-19, bem como os cuidados para evitar sua própria contaminação. É um desafio, é inédito e há um temor diante do desconhecido e do inimigo invisível. Porém, o medo é enfrentado para além do que nosso simples entendimento possa captar. Nessa fase, é preciso que os gestores já busquem intervenções por meio de aconselhamento psicológico, que pode ser realizado remotamente e ofereça dispositivos eletrônicos e aplicativos à equipe de enfermagem sobre a COVID-19(8).

\section{A recusa do chamado}

Nessa etapa, o herói, ao ser convidado ao desafio, reluta devido à magnitude, duvida de si mesmo, sente medo e não aceita o que lhe é proposto, recuando e apresentando diversos motivos para não o aceitar. Em muitas situações, deparamos com a recusa do sujeito em aceitar trabalhar nesta unidade, seja por duvidar de si mesmo ou por medo de contaminar seus familiares. Busca outras opções de trabalho e, muitas vezes, até chega a desistir de sua profissão, seja por falta de reconhecimento ou por baixa remuneração.

Denota-se que os profissionais de enfermagem se deparam cotidianamente, em seu processo laboral, com situações limite, onde executam suas atividades sobrecarregados devido a recursos humanos insuficientes, falta de recursos materiais e materiais insuficientes e, principalmente, falta de Equipamentos de Proteção Individual (EPI) para que possam prestar uma assistência com qualidade. Além disso, 
são pouco valorizados e reconhecidos, ficando expostos, diariamente, a riscos físicos, químicos, ergonômicos e mentais(10). Tais situações, somadas ao medo e insegurança, podem influenciar, sobremaneira, a recusa desses heróis para o chamamento.

\section{O auxílio sobrenatural}

Este se configura como uma ajuda, proteção e treinamento para que o herói, que volta atrás em sua decisão, por ter vivido fatos que os fez mudar de idéia, conseguindo cumprir sua tarefa. Muitas vezes, é importante recuar caso o herói não se sinta pronto para aceitar o desafio, sem a ajuda superior fornecida por figuras denominadas de "mentores". Aqui, podemos fazer um paralelo com a figura de apoio de pessoas mais experientes, como professores e enfermeiros, que se comprometem a treinar o indivíduo para que conclua sua tarefa. Até mesmo familiares, capazes de estimular e inspirar coragem no herói, são fundamentais. Sua aparição costuma ser breve na jornada do herói, mas de crucial importância.

O profissional só consegue avançar nessa jornada se conseguir ter esse apoio. Novamente, surge o enfermeiro como líder da equipe de enfermagem, capaz de incentivar e despertar para a necessidade de os heróis surgirem para enfrentar o inimigo invisível, capaz de matar muitas pessoas. Nasce o espírito de ajuda mútua, de responsabilidade, de servir ao próximo e à pátria, bem como do juramento realizado quando se formaram(11).

\section{Travessia do primeiro limiar}

Limite entre o mundo seguro e conhecido para o desafio a ser enfrentado. A pessoa teme adentrar o desconhecido, sentindo-se mais segura onde conhece. $\mathrm{O}$ profissional de enfermagem, apesar de estar sendo treinado, ainda não se sente totalmente confiante. Sente medo de não retornar, de não poder voltar para cuidar de seus filhos, ou o pior, de trazer a doença até seus entes queridos.

É um momento que revela muita ambiguidade e indecisão pela escolha que está prestes a fazer. Muitos só conseguiram superar esta etapa desligando-se de sua casa e família, indo morar em hotel ou dormir no trabalho. Esse é o momento em que o herói adentra o desafio. A partir desse momento, o herói sente-se pronto, acreditando que, mesmo rumo ao desconhecido, encontrará segurança. O enfermeiro é essencial para fortalecer a sua equipe a entender o mundo pouco conhecido do vírus que atingiu todos os países. Esses 
.

heróis em seu processo laboral vão buscando estratégias individuais e coletivas para enfrentar o inimigo microscópico comum a eles e à sociedade. Pesquisa realizada em Wuhan, China, destaca que é essencial desenvolver estratégias de enfrentamento para promover a saúde mental dos trabalhadores(12).

\section{O Ventre da Baleia (testes,}

\section{aliados e inimigos)}

Trata-se da idéia de que a passagem pelo primeiro limiar rumo a um tipo de renascimento é simbolizada pela imagem do útero ou ventre da baleia ou ser engolido por algum tipo de monstro. É jogado no desconhecido, dando a impressão que morreu, quando, na verdade, reaparece posteriormente já evoluído, tendo superado desafios. Surgem provações, descobrem-se aliados e inimigos. Muitos testes são lançados para testar o herói e prepará-lo ainda mais para desafios maiores futuros. Até a própria distinção entre aliados e inimigos é uma forma de teste.

O profissional de enfermagem encontra seus desafios, descobrindo o coleguismo e/ou a inimizade no trabalho e até aqueles que prejudicam ou sabotam suas ações e intenções. No mundo novo, ele é frequentemente testado, descobrindo seu potencial, limitações identificando

colegas e/ou subordinados quem são aliados̄s

e quem são inimigos, em quem pode confiar ou não, formando equipes ou grupos coesos. Muitas vezes, é nessa etapa em que o herói desencadeia inimizades podendo levar ao surgimento de levantes e ataques significativos à sua figura e obra. Surge, também, a figura do rival aquele que encabeça o papel opositor, que deseja a derrota de seu adversário, por buscarem o mesmo objetivo. E, por fim, o herói passa a reconhecer a existência de regras do novo mundo, até então, desconhecidas por ele.

São características muito bem conhecidas do ambiente de trabalho pela equipe de enfermagem, quando um membro adentra um novo ambiente de trabalho, experimentando conflitos, amizades, relações de confiança, rivalidades e com que velocidade é capaz de aprender e se adaptar às novas regras deste novo local. Cabe, ainda, ressaltar que os heróis em seu processo laboral vivenciam conflitos de toda natureza, mas cabe lembrar que nenhum trabalho é isento de sofrimento, de lutas, de esperanças e de $\operatorname{prazer}^{(13)}$. Assim, é preciso que no processo laboral dos profissionais de enfermagem haja espaço para ouvir e falar e, assim, buscar um labor mais saudável 
para todos os envolvidos, uma vez que cada membro da equipe constitui a sua própria jornada do herói.

\section{Aproximação da caverna oculta}

Etapa que precede 0 desafio supremo, o desafio central da sua jornada, idealizada com o propósito de fazer o herói desistir de sua jornada. Nessa fase, muitas vezes acontece o envolvimento amoroso do herói, o qual fornece o estímulo final para prosseguir sua jornada. Em outras situações, há uma chegada direta e ousada do herói, ignorando os avisos de perigo diversos. Há também os preparativos para a prova, que consistem em o herói verificar suas provisões, armas, estratégias, etc. Os heróis da enfermagem têm consciência de que o mundo precisa deles: não há como desistir da guerra imputada pela COVID-19. Aqui se dá início ao processo laboral do envolvimento, dos laços de empatia pelos pacientes$^{(14)}$ e do enfrentamento de outra dimensão.

\section{Provação suprema}

Essa etapa centra-se na mudança ou transformação total do herói. É o ponto crítico onde o herói duvida de si, chegando, muitas vezes, a quase desistir por completo, por provocar ou ser responsável por algum acontecimento que considere imperdoável.
Ele enfrenta o maior desafio de sua jornada tanto profissional quanto pessoal, que o guia para a "morte simbólica", ou seja, o abandono do "eu" passado para o surgimento de um novo "eu", integrando novos atributos de sua psique à sua consciência.

Neste raciocínio, o profissional de enfermagem pode simplesmente presenciar um óbito e julgar como sua falha, decidindo se afastar da profissão ou ainda provocar a contaminação de um colega de trabalho ou de sua própria família. Este pode se configurar como o maior desafio de sua jornada, sendo o ponto decisório para definir a continuação ou interrupção dela. Após a crise, vem a mudança, a aceitação da falha, levando-o à transformação de tal forma que o antigo herói, aquele que iniciou a jornada, renasce com outros atributos fundamentais para poder continuar sua jornada. Por exemplo, se para um determinado profissional a morte seja a maior dificuldade de lidar, devido a acontecimentos em sua vida pessoal, lidar com a morte de um paciente pode desencadear o processo de "morte" simbólica desse antigo "eu" e nascimento de um novo "eu", o que sabe aceitar e lidar com a morte.

Embora seja uma etapa de muita dor 
${ }^{-1}$

e questionamento para os heróis da enfermagem superarem, há uma vontade de superar e continuar o seu trabalho, pois não há substitutos e o senso de responsabilidade ultrapassa seus medos. Porém, há limites até para os heróis. Assim, é de fundamental importância que os gestores busquem profissionais com capacidade de atuar junto a esses heróis no sentido de promover a saúde mental e prevenir agravos à saúde de qualquer natureza. Estudo de revisão realizado na China mostrou que os profissionais de saúde apresentam depressão, ansiedade e insônia, e que esses sintomas podem ter efeitos duradouros no bem-estar desses profissionais(15).

\section{Recompensa}

Após superar a etapa anterior, o herói vivencia um período de reconhecimento e recompensa por ter sobrevivido ao desafio supremo. Nesse momento, há a posse do que se veio buscar, com a provação suprema: a "poderosa espada", o "elixir mágico", etc. Como analogia ao profissional de enfermagem, pode-se considerar aquilo que buscava encontrar, seja a coragem, abnegação, compaixão, prudência, organização, entre outros infindáveis atributos e que conseguiu obter após ter superado seu grande desafio.
Isso não significa que, em outro momento de vida, ele não inicie outra nova jornada para enfrentar outro desafio.

É preciso cautela, pois os recursos escassos podem propiciar o adoecimento desses heróis e por sua vez de seus familiares. Ressalta-se que o processo de empatia vem sendo aumentado paulatinamente entre os heróis da enfermagem e seus pacientes, mas, nessa fase, pode haver um relaxamento dos cuidados consigo mesmo, porém o ambiente está rodeado de riscos já conhecidos, somado ao risco iminente que é vírus microscópico da COVID-19. Novamente, recai para o enfermeiro, como líder, estar atento à situação. O alerta deve ser nas 24 horas, o que pode trazer consequências para a saúde mental do enfermeiro e também para sua equipe. Assim sendo, a saúde mental dos profissionais de saúde, isto é, a primeira linha de defesa contra a COVID-19, não deve ser negligenciada(16-17).

\section{Caminho de Volta}

Essa etapa trata da escolha que se faz: permanecer no cenário atual ou regressar ao seu local de origem para compartilhar o que conseguiu com sua comunidade, ou seja, voltar e aplicar o conhecimento aprendido, compartilhar as 
glórias e riquezas obtidas. Não se configura como tarefa fácil, pois a comunidade de onde ele partiu não passou pelas transformações que o herói passou, então, ainda apresenta as mesmas dúvidas e ceticismos que o próprio herói possuía quando partiu.

\section{Ressurreição}

Não obstante as transformações pelas quais o herói passou, esse último e maior desafio torna-se o final, que decidirá pelo renascimento simbólico, onde já não existe mais o antigo "eu", e passa a existir uma nova personalidade, uma que integre o antigo e o novo "eu" de forma integrada. Funciona como uma espécie de exame de verificação da mudança obtida. O desafio, passa a ter uma magnitude nunca presenciada antes, ameaçando não só a si mesmo, mas a tudo que o envolve em sua vida e até de seus entes queridos. Ele será posto à prova, vendo-se obrigado a fazer escolhas como teste para verificar se realmente aprendeu a lição nas etapas passadas, decidindo com sua nova personalidade, ao invés da antiga, realizando, muitas vezes, sacrifícios pelo bem comum ou de outros. O processo laboral da equipe de enfermagem pode, de fato, nunca mais ser o mesmo após a pandemia. Novos conhecimentos foram aprendidos e incorporados no cotidiano laboral, em especial o trabalho em equipe, para superar os obstáculos(18). Por consequência, acreditase que vá se dar um novo significado à vida profissional e a pessoal.

\section{Retorno com o elixir}

Nessa etapa, ou o herói regressa ou permanece no cenário atual. Acontece também a recompensa para aqueles que colaboraram com o herói e ao próprio herói e também a punição ao "vilão" da história. O ponto crucial dessa etapa é o elixir, aquilo que ele trouxe consigo da jornada e irá compartilhar com seu local de origem, provando que esteve realmente lá e se tornou outra pessoa, transformada.

A equipe de enfermagem já não é mais a mesma desde o início da pandemia da COVID-19, e, com certeza, muitos serão os heróis e os super-heróis, mas não há como não ressignificar a vida regredindo para o que era anteriormente. Deve-se superar e mostrar à sociedade, à comunidade científica, aos colegas, aos gestores e aos políticos o quão essencial é a enfermagem para o sistema de saúde em qualquer lugar desse mundo. O relatório da Organização Mundial de Saúde(19) aponta que "as enfermeiras e enfermeiros sempre estiveram na vanguarda 
th $+2$

de salvar vidas e cuidar das pessoas. Mas nunca antes seu valor foi mais claro do que é agora. Esses profissionais merecem não apenas nossa gratidão, mas também apoio tangível para garantir que sejam capazes de contribuir ao máximo com suas habilidades."

\section{Mundo comum}

É onde o herói, incorporado ao seu local de origem, passa a viver novamente lá, podendo, muitas vezes, sofrer a consequência de ter estado tanto tempo fora, ter se transformado e não mais se adaptar. Pode haver dificuldades de reintegração e de aceitação pelas mudanças obtidas pelo herói, que dificultam sua convivência, já que ele também não é mais o mesmo. Podem surgir sentimentos de inadequação àquele meio, fazendo com que se mude, se sinta resignado ou busque outra jornada para enfrentar outros desafios. Os heróis da enfermagem atuais são conhecedores de como surgiu a sua profissão(20) (Florence Nightingale e a Guerra da Criméia), o que não é diferente do que se está enfrentando com a pandemia. Após a guerra da Crimeia, a enfermagem seguiu um novo rumo, e não será diferente desta vez, pois está estampado a nível mundial que sem esses profissionais não seria possível enfrentar a COVID-19. Cabe a cada profissional de enfermagem refletir sobre o herói que esteve em maior ou menor grau dentro dele e buscar novos processos laborais que busquem maximizar o bem-estar de todos.

\section{CONSIDERAÇÕES FINAIS}

Os heróis são apresentados no mundo comum, onde recebem um chamado à aventura. Primeiro, ficam relutantes ou recusam o chamado, mas, em um encontro com o mentor, são encorajados a fazer a travessia do primeiro limiar e entrar no mundo especial, onde encontram testes, aliados e inimigos. Na aproximação da caverna oculta, cruzam um segundo limiar, no qual enfrentam a provação, ganham sua recompensa e são perseguidos no caminho de volta ao mundo comum. Cruzam, então, o terceiro limiar, experimentam uma ressurreição e são transformados pela experiência. Chega, então, o momento do retorno com o elixir, a bênção ou o tesouro que beneficia o mundo comum.

Essas etapas são vivenciadas no processo laboral da enfermagem. Porém, não houve mais heróis ou menos heróis, pois todos foram e são importantes no enfrentamento dessa pandemia. Dessa forma, todos de fato foram heróis que, 
mesmos desconhecidos e pouco valorizados, passaram a ter visibilidade para a sociedade diante de uma catástrofe mundial. Além disso, antes da notícia da pandemia, a Organização Mundial da Saúde já havia estipulado o ano de 2020 como o ano de empoderamento da enfermagem.

Aos heróis da enfermagem, cabe revelar o que vivenciaram: as suas superações, os seus anseios e suas vitorias. É um momento de mostrar ao mundo que os heróis sempre foram heróis, mas pouco reconhecidos e valorizados pela sociedade, por outros profissionais de saúde, bem como a sociedade civil de uma forma geral. É preciso que a sociedade volte sua atenção e reflita sobre a essencialidade de enfermagem e demais profissionais da área da saúde, em especial a enfermagem, por estar com os pacientes 24 horas ininterruptamente.

Por fim, o objetivo deste texto foi de levar à categoria um processo reflexivo de forma que contribuísse para elevar a moral profissional em um momento tão doloroso, mas que será transformador para toda a sociedade.

\section{REFERÊNCIAS}

1. Bauman Z. Vida Líquida. RJ: Zahar; 2007.

2. Vázquez-Colunga, JC et al. Saúde Mental Positiva Ocupacional: proposta de modelo teórico para abordagem positiva da saúde mental no trabalho. Saúde Soc. [Internet]. 2017 [acesso 11 Mai 2020]; 584-595. Available from: https://doi.org/10.1590/S0104-12902017169061

3. Jung CG. O homem e seus símbolos. RJ: Harper Collins; 2016.

4. Jung CG. Os arquétipos e o inconsciente coletivo. 11.ed. RJ: Vozes; 2014

5. Jung CG. Tipos psicológicos. 6.ed. SP: Vozes, 2016.

6. Campbell, J. O herói de mil faces. SP: Cultrix; 1997.

7. Muller, L. O herói: a verdadeira jornada do herói e o caminho da individuação. SP: Cultrix; 2007.

8. Yang Y, Li W, Zhang Q, Zhang L, Cheung T, Xiang YT. Mental health services for older adults in China during the COVID-19 outbreak. Lancet Psychiatry [Internet]. 2020 [acesso 11 mai 2020];7:e19. Available from: https://www.thelancet.com/action/showPdf?pii=S 2215-0366\%2820\%2930079-1

9. Xiao C. A novel approach of consultation on 2019 novel coronavirus (COVID-19)-related psychological and mental problems: structured letter therapy. Psychiatry Investig [Internet]. 2020 [acesso 11 mai 2020];17:175-6. Available from:

https://www.ncbi.nlm.nih.gov/pmc/articles/PMC7 047000/pdf/pi-2020-0047.pdf 
10. Scozzafave MCS et al . Riscos psicossociais relacionados ao enfermeiro no hospital psiquiátrico e estratégias de gerenciamento. Rev Bras Enferm [Internet]. 2019. [acesso 11 mai 2020]; 72(4):834-840. Available from http://www.scielo.br/scielo.php?script=sci_arttext \&pid $=$ S0034-

$1672019000400834 \&$ Ing $=p t \& n r m=$ iso

11. Peduzzi M, Oliveira MAC, Silva JAM, Agreli HLF, Miranda Neto MV. Trabalho em equipe, prática e educação interprofissional. In: Martins MA, Carrilho FJ, Alves VAF, Castilho EA, Cerri GG, editores. Clínica médica. $2^{a}$ ed. Barueri: Manole; 2016. p.171-9.

12. Kang L, Li Y, Hu S, Chen M, Yang C, Yang BX, et al. The mental health of medical workers in Wuhan, China dealing with the 2019 novel coronavirus. Lancet Psychiatry [Internet]. 2020 [acesso 11 mai 2020];7:e14. Available from: https://www.thelancet.com/journals/lanpsy/article /PIIS2215-0366(20)30047-X/fulltext

13. Dejours C. Uma nova visão do sofrimento humano nas organizações. In: Chanlant JT, organizador. $\mathrm{O}$ indivíduo na organização: dimensões esquecidas. São Paulo: Atlas 1993.

14. Terezam R, Reis-Queiroz J, Hoga LAK. A importância da empatia no cuidado em saúde e enfermagem. Rev Bras Enferm [Internet]. 2017. [acesso 11 mai 2020];70(3):669-70. Available from:

https://www.scielo.br/scielo.php?pid=S0034-

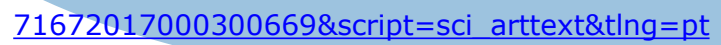

15. Shiozawa P, Uchida RR. An updated systematic review on the coronavirus pandemic: lessons for psychiatry. Braz J Psychiatry, [Internet]. 2020 [acesso 11 mai 2020]; epub 30. Available from http://www.scielo.br/scielo.php?script=sci arttext \&pid $=S 1516-$ 44462020005011202\&lng =pt\&nrm =iso
16. Lima CK, Carvalho PM, Lima IA, Nunes JV, Saraiva JS, de Souza RI, et al. The emotional impact of Coronavirus 2019-nCoV (new Coronavirus disease). Psychiatry Res [Internet]. 2020 [acesso 11 mai 2020];287:112915. Available from: https://www.sciencedirect.com/science/article/pii/ S0165178120305163?via\%3Dihub

17. Lai J, Ma S, Wang Y, Cai Z, Hu J, Wei N, et al. Factors associated with mental health outcomes among health care workers exposed to Coronavirus disease 2019. JAMA Netw Open [Internet]. 2020 [acesso 11 mai 2020];3:e203976. Available from: https://www.sciencedirect.com/science/article/pii/ S0165178120305163?via\%3Dihub

18. Souza GC, Peduzzi M, Silva JAM, Carvalho BG. Teamwork in nursing: restricted to nursing professionals or an interprofessional collaboration. Rev Esc Enferm USP [Internet]. 2016 [acesso 11 mai 2020];50(4):640-647. Available from: https://www.scielo.br/pdf/reeusp/v50n4/pt 00806234-reeusp-50-04-0642.pdf

19. World Health Organization (WHO). States of the World's Nursing 2020: investing in education, jobs and leadership. Geneva: WHO [Internet]. 2020 [acesso 11 mai 2020]. Available from https://www.who.int/publications-detail/nursingreport-2020

20. Frello AT, Carraro TE. Contribuicões de Florence Nightingale: uma revisao integrativa da literatura. Esc. Anna Nery [Internet]. 2013. [acesso 11 mai 2020]; 17(3):573-579. Available from:

http://www.scielo.br/scielo.php?script=sci arttext \&pid $=S 1414$ -

$81452013000300573 \& \mathrm{lng}=\mathrm{en} \& \mathrm{nrm}=\mathrm{iso}$ 